\title{
A Single Dose of Beetroot Juice Does Not Change Blood Pressure Response Mediated by Acute Aerobic Exercise in Hypertensive Postmenopausal Women
}

\author{
Ana Luiza Amaral ${ }^{1}$, Igor M. Mariano ${ }^{1}\left(\mathbb{D}\right.$, Victor Hugo V. Carrijo ${ }^{1}$, \\ Tállita Cristina F. de Souza ${ }^{1} \mathbb{D}$, Jaqueline P. Batista ${ }^{1}$, Anne M. Mendonça ${ }^{1,2,3,4}$, \\ Adriele V. de Souza ${ }^{5}$, Douglas C. Caixeta ${ }^{5}$, Renata R. Teixeira ${ }^{5}$, Foued S. Espindola ${ }^{5}(\mathbb{D}$, \\ Erick P. de Oliveira ${ }^{2}$ and Guilherme M. Puga ${ }^{1, * \mathbb{D}}$ \\ 1 Laboratory of Cardiorespiratory and Metabolic Physiology, Federal University of Uberlândia, Uberlândia, \\ MG 38400-678, Brazil; anaribeiro.am@gmail.com (A.L.A.); igormmariano@gmail.com (I.M.M.); \\ vilarinhovictorh@gmail.com (V.H.V.C.); tallita_crystina@hotmail.com (T.C.F.d.S.); \\ jaquebpontes@gmail.com (J.P.B.); annemarques.m@hotmail.com (A.M.M.) \\ 2 School of Medicine, Federal University of Uberlândia, Uberlândia, MG 38400-902, Brazil; \\ erick_po@yahoo.com.br \\ 3 Department of Food and Human Nutritional Sciences, University of Manitoba, \\ Winnipeg, MB R3T 2N2, Canada \\ 4 Canadian Centre for Agri-Food Research in Health and Medicine, St. Boniface Hospital Research Centre, \\ Winnipeg, MB R2H 2A6, Canada \\ 5 Laboratory of Biochemistry and Molecular Biology, Institute of Biotechnology, Federal University of \\ Uberlândia, Uberlândia, MG 38400-902, Brazil; adriele_vds@hotmail.com (A.V.d.S.); \\ caixetadoug@gmail.com (D.C.C.); rolandteixeira@yahoo.com (R.R.T.); fsespindola@gmail.com (F.S.E.) \\ * Correspondence: gmpuga@gmail.com; Tel.: +55-34-3218-2967
}

Received: 30 April 2019; Accepted: 4 June 2019; Published: 13 June 2019

\begin{abstract}
Objective: To verify if acute intake of beetroot juice potentiates post-exercise hypotension $(\mathrm{PEH})$ in hypertensive postmenopausal women. Methods: Thirteen hypertensive postmenopausal women $\left(58.1 \pm 4.62\right.$ years and $\left.27.4 \pm 4.25 \mathrm{~kg} / \mathrm{m}^{2}\right)$ were recruited to participate in three experimental sessions, taking three different beverages: Beetroot juice (BJ), placebo nitrate-depleted BJ (PLA), and orange flavored non-caloric drink (OFD). The participants performed moderate aerobic exercise training on a treadmill, at $65-70 \%$ of heart rate reserve (HRR), for $40 \mathrm{~min}$. After an overnight fast, the protocol started at $07 \mathrm{~h}$ when the first resting blood pressure (BP) was measured. The beverage was ingested at $07 \mathrm{~h} 30$ and BP was monitored until the exercise training started, at 09h30. After the end of the exercise session, BP was measured every 15 min over a $90-$ min period. Saliva samples were collected at rest, immediately before and after exercise, and $90 \mathrm{~min}$ after exercise for nitrite $\left(\mathrm{NO}_{2}{ }^{-}\right)$analysis. Results: There was an increase in salivary $\mathrm{NO}_{2}{ }^{-}$with $\mathrm{BJ}$ intake when compared to OFD and PLA. A slight increase in salivary $\mathrm{NO}_{2}{ }^{-}$was observed with PLA when compared to OFD $(p<0.05)$, however, PLA resulted in lower salivary $\mathrm{NO}_{2}{ }^{-}$when compared to $\mathrm{BJ}(p<0.001)$. There were no changes in salivary $\mathrm{NO}_{2}{ }^{-}$with the OFD. Systolic and diastolic BP decreased $(p<0.001)$ on all post exercise time points after all interventions, with no difference between the three beverages. Conclusion: Acute BJ intake does not change PEH responses in hypertensive postmenopausal women, even though there is an increase in salivary $\mathrm{NO}_{2}{ }^{-}$.
\end{abstract}

Keywords: nitrite; nitric oxide; hypertension; menopause; Post Exercise Hypotension 


\section{Introduction}

There are several physiological changes in women's body during climacteric period, including reduction of estrogen levels and menstruation cessation (menopause). As estrogen is a cardioprotective hormone [1], subsequent to its reduction, there is an increased risk of developing cardiometabolic diseases, due to reduced vasodilatation, increased blood pressure (BP), oxidative stress, and inflammation [2].

Hypertension is one of the most prevalent cardiometabolic diseases after menopause [3], and pharmacological therapy is the most common treatment approach. However, changes in lifestyle, such as developing healthy dietary habits and performing exercise regularly, are important factors for hypertension prevention and control [3]. The practice of regular physical exercise can reduce resting $\mathrm{BP}$ chronically, and induce post-exercise hypotension (PEH), which is a reduction in BP below resting values after exercise training. This phenomenon is clinically relevant in the prevention and treatment of cardiovascular diseases, and in the reduction of cardiovascular events [4]. This cardiovascular regulatory response has been related to endothelium-derived nitric oxide (NO) [4,5]. Exercise-induced shear stress promotes the release of calcium by endothelial cells, from which the calcium binds to calmodulin and stimulates endothelial nitric oxide synthase (eNOS) to reduce L-arginine to NO, where NO is directly involved in vascular tone regulation and homeostasis [5].

During exercise, NO release induces vasodilation, increasing blood flow to skeletal muscles and regulating blood pressure [5]. In addition, consumption of foods containing inorganic nitrate $\left(\mathrm{NO}_{3}{ }^{-}\right)$ can increase $\mathrm{NO}$ bioavailability. This increase occurs by the initial conversion of $\mathrm{NO}_{3}{ }^{-}$into nitrite $\left(\mathrm{NO}_{2}{ }^{-}\right)$in the mouth and stomach, through non-enzymatic reactions. $\mathrm{The}^{\mathrm{NO}_{2}}{ }^{-}$is then released into the systemic circulation for subsequent NO production [6], leading to improvements in hemodynamic regulation. Therefore, consumption of foods rich in $\mathrm{NO}_{3}{ }^{-}$may be a good strategy to improve $\mathrm{BP}$ regulation in target populations with an increased incidence of cardiometabolic diseases, especially when associated with exercise [7-12], since these two pathways of NO production can complement each other [6].

A common food that has a high $\mathrm{NO}_{3}{ }^{-}$concentration is beetroot, and some effects observed with beetroot juice (BJ) consumption are related to improvement in blood flow, vasodilation, and reduction of BP [13-15]. The majority of studies that investigated BJ ingestion are related to sports and exercise performance [16-19], and only a few studies explored BJ consumption in parameters of health, in non-athletic populations, such as evaluating hemodynamic parameters in patients with chronic cardiorespiratory diseases $[16,20]$. These results are still inconclusive, since one did not find PEH with BJ consumption [20], and the other found PEH only in diastolic BP (DBP) [16]. Moreover, there is a lack of studies evaluating BJ benefits for hypertensive post-menopausal women. This population is of interest because there is a reduction in NO production, both due to hypertension and decreased estrogen levels.

Therefore, the purpose of this study was to verify if $\mathrm{BJ}$ ingestion has additional effects on $\mathrm{PEH}$ after one aerobic exercise session, and its relationship with salivary $\mathrm{NO}_{2}{ }^{-}$in hypertensive postmenopausal women. Our hypothesis was that BJ would improve blood pressure response after exercise in hypertensive postmenopausal women, due to an increase in the NO pathway, measured by salivary $\mathrm{NO}_{2}{ }^{-}$levels.

\section{Materials and Methods}

\subsection{Participants}

The study intervention was conducted between June and September 2018, at the Laboratory of Cardiorespiratory and Metabolic Physiology of the Federal University of Uberlândia, Uberlândia, MG, Brazil. This study design was approved by the local Ethics Committee (70104717.0.0000.5152) and registered at Clinicaltrials.gov (NCT03620227). All participants agreed and signed an informed consent form prior to admission. 
For the inclusion criteria, participants were required to be: in post menopause (amenorrhea for at least 12 months and [FSH] $>40 \mathrm{mIU} / \mathrm{mL}$ ); diagnosed with hypertension, according to the 7th Brazilian Arterial Hypertension Directive [3], which is defined by baseline blood pressure values greater than or equal to $140 \mathrm{mmHg}$ for systolic BP (SBP) and $90 \mathrm{mmHg}$ for DBP; aged between 50 and 70 years, and able to perform exercises on a treadmill. The exclusion criteria consisted of: use of hormonal therapy; history of food allergies that could compromise the study; sensitivity to $\mathrm{NO}_{3}{ }^{-}$; history of stroke or acute myocardial infarction; diagnosis of Diabetes Mellitus; and smoking habits. Although all the volunteers used antihypertensive drugs, they were excluded if they were taking drugs of the $\beta$-blocker class. All participants went through a cardiological evaluation with a specialist before the intervention, obtaining a certificate to attest individual suitability for exercise practice. Exclusion criteria also applied to volunteers who failed to perform the protocol test, with some of the reasons, including intolerance to the exercise program, inability to ingest the juice, or inability to go through the fasting time.

The number of volunteers required for this trial was calculated considering BP variation caused by BJ relative to placebo (PLA) as the main variable, with a variation of $5 \pm 4 \mathrm{mmHg}$ defined as an acceptable effect [13]. Using online software (OpenEpi), considering a bilateral $95 \%$ confidence interval, and power analysis of $80 \%$, a minimum of 11 people were needed for this study. After the calculation, 15 volunteers were recruited to participate in this study. Two out of the 15 volunteers were excluded from the study for inability to adapt to the study protocol, due to an abrupt decrease in blood pressure followed by initial syncope as of $15 \mathrm{~min}$ after the beginning of the first exercise session. One of the volunteers had consumed BJ and the other PLA.

The study volunteers answered both an anamnesis and a physical activity questionnaire (IPAQ short version). Anthropometric measures included: body mass (Filizola electronic scale); height (fixed stadiometer Sanny); abdominal circumference (Filizola inelastic tape); and body composition (bioimpedance Inbody 230, Seoul, Coreia do Sul), assessed as previously described [21]. For the body composition measurement, all participants were instructed not to perform vigorous physical exercise $24 \mathrm{~h}$ before the test and to avoid alcohol and caffeine consumption $72 \mathrm{~h}$ before the test.

\subsection{Study Design}

The present study was a double blind randomized, placebo-controlled, and crossover trial. The intervention comprised a total of three visits with a minimum wash-out interval of five days in between visits. In each visit, one of the following beverages was taken: Placebo (PLA), non-caloric orange flavor drink (OFD), or Beetroot Juice (BJ). Volunteers arrived in the laboratory at 07:00. and left at 11:40. Figure 1 illustrates the experimental design of the sessions.

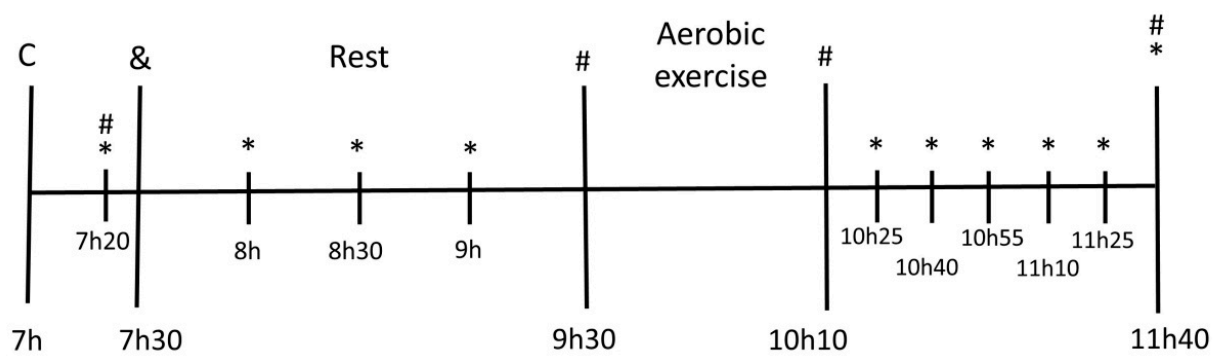

Figure 1. Experimental design of the sessions. (C) Arrival at the laboratory; $\left({ }^{*}\right)$ Blood pressure measurement; (\#) Saliva sample collection; (\&) Beverage intake.

During all intervention sessions, the volunteers arrived at 07:00, after eight hours of an overnight fast. BP was measured after $20 \mathrm{~min}$ of rest in a sitting position (07:20), every $30 \mathrm{~min}$ after the beverage intake until the beginning of the exercise (08:00, 08:30, and 09:00), and every $15 \mathrm{~min}$ for $90 \mathrm{~min}$ after the exercise session. Unstimulated saliva samples were collected after the $20 \mathrm{~min}$ of rest $(07: 20)$, immediately before (09:30) and after (10:10) exercise, and $90 \mathrm{~min}$ after the exercise session was finished 
(11:40). Heart rate (HR) was measured during the 20 min of rest (between 07:00 and 07:20), during the exercise, and during the $90 \mathrm{~min}$ after the exercise session (Polar ${ }^{\circledR} \mathrm{RS} 800 \mathrm{CX}$ ). The beverage intake took place $10 \mathrm{~min}$ after the rest period (07:30), allowing $15 \mathrm{~min}$ for the consumption of all the beverage content. The exercise session was 40 min long (from 09:30 to 10:10).

During the sessions, the volunteers were allowed to drink water, but no other drink or food ingestion was permitted. They were instructed to avoid foods and drinks rich in $\mathrm{NO}_{3}{ }^{-} 24 \mathrm{~h}$ before the sessions and received a list with the following consumption restrictions: Green vegetables (amaranth, lettuce, cabbage, spinach, broccoli, celery, cauliflower, Chinese radish), beetroot or its juice, sausage, salami, ham, turkey breast, coffee, energy drinks, soft drinks, alcoholic beverages, and to avoid the use of mouthwashes. Before starting each intervention session, volunteers were questioned about these items.

\subsection{Physical Exercise}

The exercise consisted of $40 \mathrm{~min}$ of continuous moderate intensity aerobic exercise on a treadmill, allowing the first five minutes to warm-up and the last two minutes to cool down. The treadmill speed could reach $5.5 \mathrm{~km} / \mathrm{h}$ and the intensity increase was imposed by inclining the treadmill until the volunteer reached the zone between $65 \%$ and $70 \%$ of HR reserve (HRR) [22]. For the HRR calculation, we used the formula: maximum HR-resting HR. For the participants resting HR, we considered the minimum HR measured during the initial $20 \mathrm{~min}$ of rest on the first intervention day, and the maximum HR was estimated by the formula: 220 - age.

HR was monitored during the exercise and the Borg Scale [23] was used to assess the subjective perception of exertion (RPE) for both dyspnea and lower limb fatigue. The measurements for HR and RPE were assessed every two minutes. Whenever the HR was found to be outside of the stipulated zone, the exercise load was readjusted.

\subsection{Intake of Beetroot Juice and Placebo}

The intervention included three different juices: BJ, PLA and OFD, with one beverage assigned to each intervention session. The order of beverage intake was randomly assigned for each of the volunteers using a randomized block design through the website (https://www.random.org/lists/). For the randomization, codes were assigned to each volunteer, each beverage, and each session. Thereafter, the beverage each volunteer would drink on the first session, second and third sessions were randomly allocated in this order. A researcher who did not participate in the data collection process was responsible for assigning a beverage to each code and blinding the drinks, adding each drink to its respective bottle labeled with the volunteer's name.

The BJ had $20.78 \mathrm{mmol} / \mathrm{kg}$ of $\mathrm{NO}_{3}{ }^{-}$and was prepared using $35 \mathrm{~mL}$ of $\mathrm{NO}_{3}{ }^{-}$concentrated beetroot juice containing $400 \mathrm{mg}$ of $\mathrm{NO}_{3}{ }^{-}$(Beet-It Sport Shot, James White Drinks Ltd., Ipswich, UK), which was diluted in $315 \mathrm{~mL}$ of distilled water with $6 \mathrm{~g}$ of non-caloric orange juice flavored powder (Clight, Mondelez International, Inc., São Paulo, Brazil), totalizing $350 \mathrm{~mL}$ of juice. The PLA had $3.86 \mathrm{mmol} / \mathrm{kg}$ of $\mathrm{NO}_{3}{ }^{-}$and was prepared by filtering the $\mathrm{BJ}$ on an ion exchange resin, capable of depleting the $\mathrm{NO}_{3}{ }^{-}$ (PA101 OH-, Permution ${ }^{\circledR}$ ) [24], similarly to a previous report [25]. Lastly, the OFD was a non-caloric orange flavored drink, prepared using three grams of orange juice powder diluted in $350 \mathrm{~mL}$ of distilled water. BJ and PLA were identical in taste, while OFD was slightly different. Each volunteer received the designated drink in a sealed bottle with a lid and a dark straw, making it impossible to visualize or smell the bottle content. The study participants had 15 min to drink the entire beverage.

\subsection{Measurements of Blood Pressure}

BP was measured in a sitting position, without visual or sound stimulation, using $O M R O N^{\circledR}$ BP HEM-7113 automatic monitors. Prior to the BP measurement, 20 min of rest was required. BP was measured three times, always in the left arm, and the mean of these measures was calculated for data analysis. 


\subsection{Salivary Samples Collection and Analysis}

Saliva samples were collected using the spit method [26]. All samples were centrifuged at $3000 \mathrm{rpm}$ for $15 \mathrm{~min}$, the supernatant was separated and stored at $-80{ }^{\circ} \mathrm{C}$ until analysis. $\mathrm{The}^{\mathrm{NO}_{2}}{ }^{-}$concentration was used to estimate the bioavailability of NO by the Griess method [27].

\subsection{Statistical Analysis}

Statistical analyses were performed while researchers were blinded regarding the ingested beverage. Results are presented as mean \pm standard deviation. The Shapiro-Wilk test was applied to verify data normality, and two-way ANOVA was used to analyze differences between the time points (pre and post exercise) and the treatments (PLA, OFD, BJ), using the Bonferroni post hoc when necessary. The area under the curve (AUC) by the trapezoidal method was used to compare the temporal changes of BP and salivary $\mathrm{NO}_{2}{ }^{-}$, separately. One-way ANOVA was used for AUC and exercise analysis, and a Pearson correlation was used to assess $\mathrm{BP}$ and $\mathrm{NO}_{2}{ }^{-}$effects. Statistical significance was set at $p<0.05$. All analyses were performed using SPSS version 20 (IBM SPSS, Chicago, IL, USA) and GraphPad Prism 6 (GraphPad Prism Inc., San Diego, CA, USA).

\section{Results}

This study was completed by 13 postmenopausal women who were overweight, medically treated for hypertension, and physically active. The general characteristics of the volunteers are described in Table 1. There was no difference in exercise intensity between the sessions. For PLA, OFD, and BJ sessions, the HR mean was $125.6 \pm 7.2 ; 126.1 \pm 7.8 ; 126.7 \pm 7.4 \mathrm{bpm}(p=0.658)$; the treadmill inclination was $3.4 \pm 3.0 ; 3.5 \pm 2.7 ; 3.3 \pm 2.7 \%(p=0.715)$; the RPE of dyspnea was $3.7 \pm 0.85 ; 3.4 \pm 1.0 ; 3.4 \pm 1.0$ $(p=0.328)$; and the RPE of lower limb fatigue was $4.1 \pm 1.2 ; 3.9 \pm 1.12 ; 3.8 \pm 1.1(p=0.642)$, respectively.

Table 1. General characteristics of the participants. BMI: Body mass index. The general characteristics values are shown as mean \pm standard deviation (SD), physical activity level and drugs are shown as: number of subjects (n) and percentage of the total number of subjects (\%).

\begin{tabular}{|c|c|}
\hline General Characteristics & $($ Mean \pm SD) \\
\hline Age (years) & $58.1 \pm 4.6$ \\
\hline Body mass $(\mathrm{kg})$ & $69.9 \pm 9.2$ \\
\hline Height $(\mathrm{m})$ & $1.57 \pm 0.05$ \\
\hline $\operatorname{BMI}\left(\mathrm{kg} / \mathrm{m}^{2}\right)$ & $27.4 \pm 4.2$ \\
\hline Waist circumference $(\mathrm{cm})$ & $92.9 \pm 11.7$ \\
\hline Body fat $(\%)$ & $37.3 \pm 6.2$ \\
\hline Fat mass $(\mathrm{kg})$ & $26.1 \pm 6.9$ \\
\hline Lean mass $(\mathrm{kg})$ & $29.9 \pm 9.2$ \\
\hline Physical activity level & (n $(\%))$ \\
\hline Very Active & $2(15 \%)$ \\
\hline Active & $8(62 \%)$ \\
\hline Irregularly Active & $3(23 \%)$ \\
\hline Drugs & $(\mathrm{n}(\%))$ \\
\hline Angiotensin 1 Receptor Blockers + Diuretic & $6(46 \%)$ \\
\hline Angiotensin 1 Receptor Blockers & $4(31 \%)$ \\
\hline Diuretic & $1(8 \%)$ \\
\hline Angiotensin Converting Enzyme Inhibitor & $1(8 \%)$ \\
\hline Angiotensin Converting Enzyme Inhibitor + Diuretic & $1(8 \%)$ \\
\hline Statins & $3(23 \%)$ \\
\hline Levothyroxine & $4(31 \%)$ \\
\hline
\end{tabular}

Figure 2 illustrates the results for salivary $\mathrm{NO}_{2}{ }^{-}$. Participants had similar values during the sessions for salivary $\mathrm{NO}_{2}{ }^{-}$at rest. Before exercise, salivary $\mathrm{NO}_{2}{ }^{-}$was slightly increased $(1.0 \mathrm{mM})$ 
by PLA and greatly increased by BJ $(2.6 \mathrm{mM})(p<0.05)$, while the values remained at a low level with OFD intake $(0.1 \mathrm{mM})$. BJ lead to the highest salivary $\mathrm{NO}_{2}{ }^{-}$level $(3.3 \mathrm{mM})$ immediately after exercise when compared to the other beverages (PLA 0.9; OFD $0.1 \mathrm{mM})(p<0.01)$. Furthermore, salivary $\mathrm{NO}_{2}{ }^{-}$remained increased for up to $90 \mathrm{~min}$ post exercise with $\mathrm{BJ}$ intake when compared to rest $\left(\right.$ REST $=0.1 \pm 0.1 ;$ POST $0^{\prime}=3.3 \pm 1.3 ;$ POST 90 $\left.=2.5 \pm 1.1 \mathrm{mM} ; p<0.001\right)$, but with PLA salivary $\mathrm{NO}_{2}{ }^{-}$was only increased until immediately after exercise when compared to rest (REST $=0.2 \pm 0.1$; POST $0^{\prime}=0.9 \pm 0.6 ;$ POST $90^{\prime}=0.7 \pm 0.4 \mathrm{mM} ; p=0.011$ ). The AUC for $\mathrm{NO}_{2}{ }^{-}$response over time was the highest with BJ when compared to both PLA and OFD $(p<0.01)$, however the response was still higher with PLA when compared to OFD $(p=0.037)$. There was no correlation between salivary $\mathrm{NO}_{2}{ }^{-}$ and BP (SBP $p=0.749, r=0.053$; DBP $p=0.618, r=-0.082)$.

A

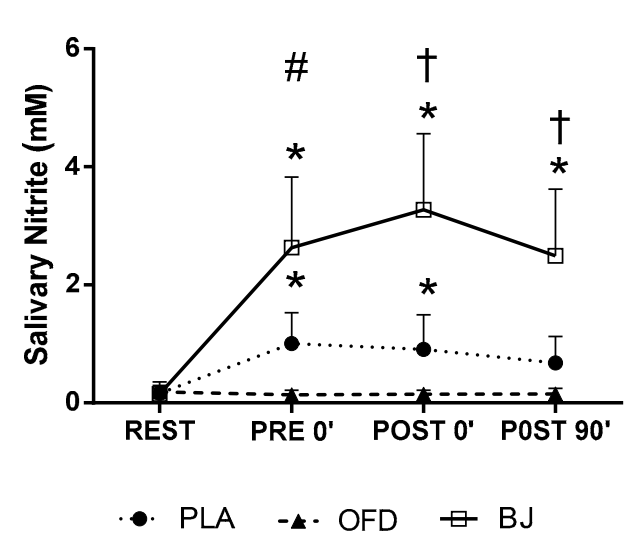

\section{B}

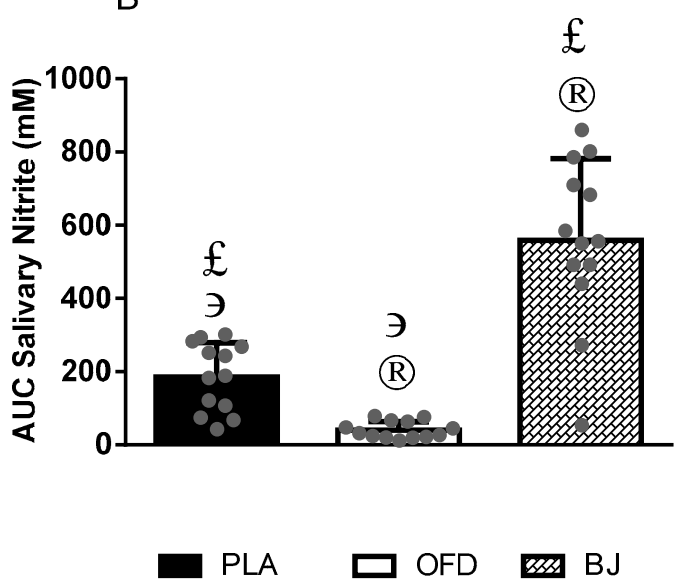

Figure 2. Salivary $\mathrm{NO}_{2}{ }^{-}$values from point to point (A) and values for the area under the curve (AUC) (B). Placebo $\mathrm{NO}_{3}{ }^{-}$depleted beetroot juice (PLA); Non-caloric orange flavored drink (OFD); Beetroot juice (BJ). (\#) significantly different between all sessions; ( $($ ) significantly different when comparing BJ with both PLA and OFD; $\left(^{*}\right)$ significantly different when compared to rest (REST); (®) significantly different when compared to PLA; (э) significantly different when compared to BJ; (£) significantly different when compared to OFD.

Figure 3 shows the SBP, DBP and HR responses throughout the experimental sessions. SBP increased after beverage consumption when compared to rest $(p=0.001)$ and decreased after exercise when compared to both rest and post ingestion time points. DBP also increased after beverage intake $(p=0.001)$ and decreased in the three following time points after exercise when compared to rest $(p=0.005)$. All DBP values decreased after exercise when compared to the pre-exercise value $(p=0.001)$. An increase in HR was observed after exercise when compared to rest $(p=0.001)$. There was no difference in SBP, DBP or HR between the three experimental sessions $(p=1.000)$.

Figure 4 demonstrates the BP variation after exercise in comparison with the BP measured at rest, 30 min before the exercise (at 9:00 am, as shown in Figure 1) and its respective AUC. SBP and DBP decreased in all evaluated time points post-exercise $(p<0.001)$. No difference for the AUC was observed among sessions $(p=1.000)$. 

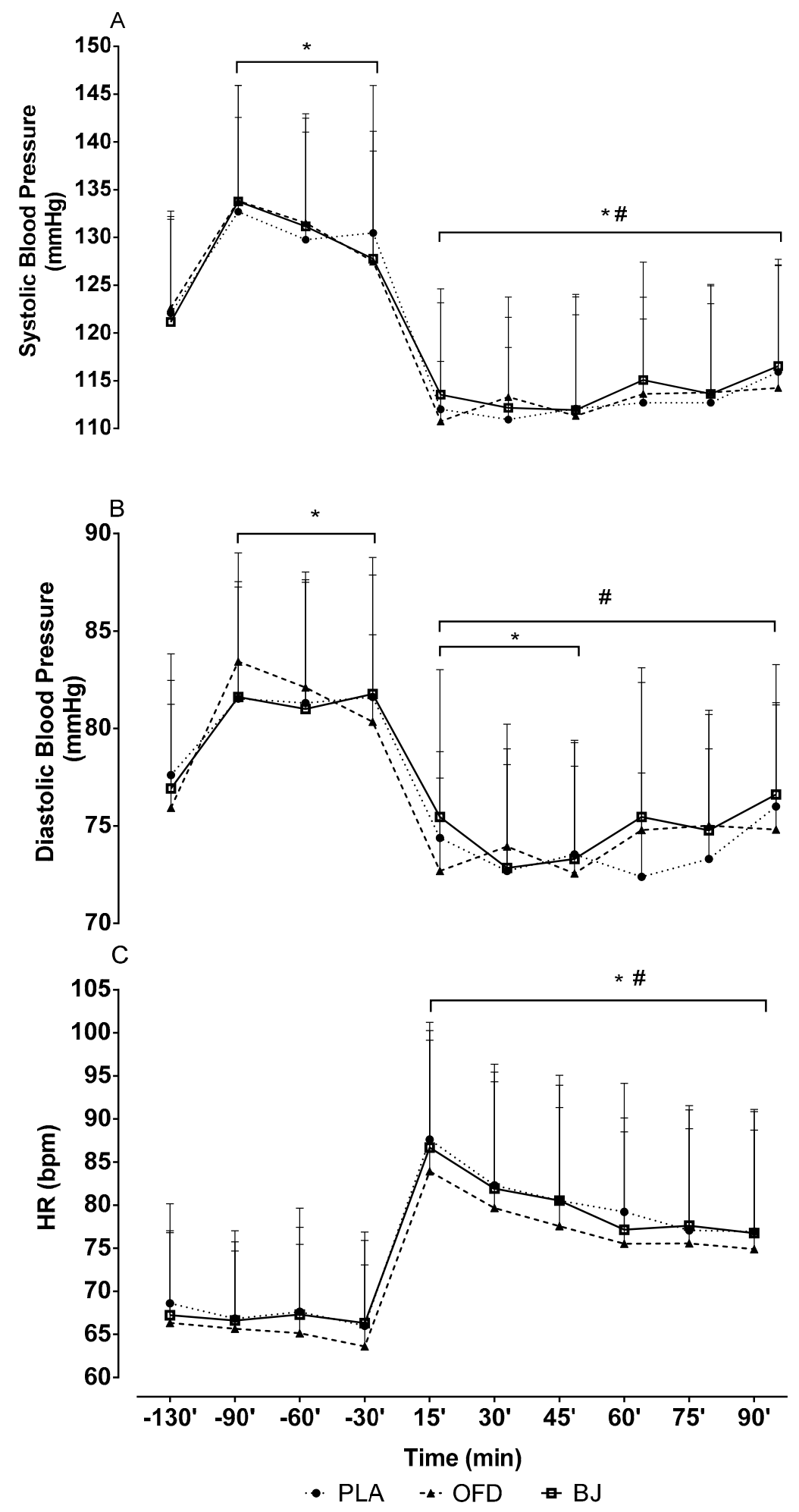

Figure 3. Systolic blood pressure (A); diastolic blood pressure (B) and point-to-point heart rate (C). Placebo $\mathrm{NO}_{3}{ }^{-}$depleted beetroot juice (PLA); Non-caloric orange flavor drink (OFD); Beet juice (BJ). The negative time values refer to measurements before exercise. The positive time values refer to measurements after the exercise. ${ }^{*}$ ) significantly different when compared to the $-130^{\prime}$ timepoint (resting pre-ingestion); (\#) significantly different when compared to the $-90^{\prime},-60^{\prime},-30^{\prime}$ timepoints (post juice intake). 

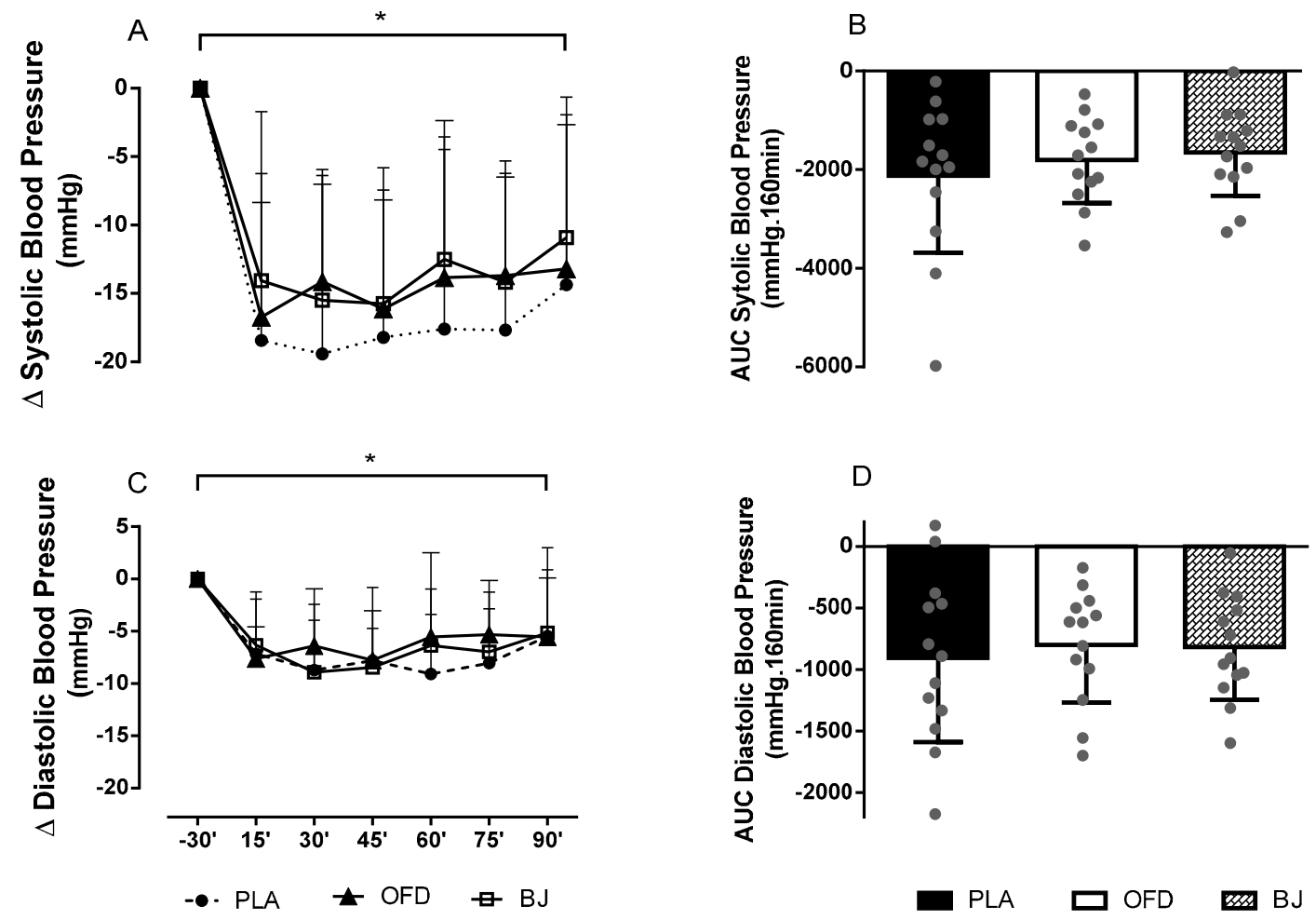

Figure 4. $\Delta$ values for systolic blood pressure variation (A) and diastolic blood pressure variation (C), area under the curve (AUC) for systolic blood pressure (B) and for diastolic blood pressure (D). Placebo $\mathrm{NO}_{3}{ }^{-}$depleted beetroot juice (PLA); Non-caloric orange flavor drink (OFD); Beetroot juice (BJ). The negative time values refer to measurements before exercise. The positive time values refer to measurements after the exercise. (*) significantly different when compared to the $-30^{\prime}$ point (pre-exercise).

\section{Discussion}

The hypothesis underlying this study was that an increase in $\mathrm{NO}_{2}{ }^{-}$, due to $\mathrm{BJ}$ intake would enhance NO bioavailability, consequently increasing vasodilation and improving BP reduction mediated by exercise in hypertensive postmenopausal women. The main findings of the study were that a moderate-intensity aerobic exercise session was sufficient to cause $\mathrm{PEH}$, and that acute BJ intake did not lead to additional effects on $\mathrm{PEH}$, even though there was an increase in salivary $\mathrm{NO}_{2}{ }^{-}$, which could result in enhanced NO bioavailability.

To the best of our knowledge, this is the first study with hypertensive postmenopausal women analyzing acute intake of BJ and its influence on BP. Several other interventions assessing effects of BJ intake have been completed with different populations. Previous studies have investigated chronic [7-12,28] and acute BJ ingestion [16,20,28-30], in athletes [17-19], in healthy non-athletes [31,32], and in patients in disease states [7-12,16,20]. BJ consumption has been analyzed combined with exercise [28,33] and without exercise [34]. Usually, the primary objective of these studies is to evaluate the oxygen consumption and blood flow [28], associated with the analysis of plasma or salivary $\mathrm{NO}_{2}{ }^{-}$. Although BJ supplementation may cause a significant reduction in BP and this is usually evaluated as a secondary outcome, we can still cross-compare these studies with ours.

A recent review [6] discussed different study designs for BJ intervention and BP response in non-athlete populations. A meta-analysis showed that elderly people had less accentuated hypotensive responses [35], however, this is not a consensus, since another meta-analysis [13] showed an opposite effect. Other characteristics that may influence these results are both sex (women have less evident responses) and BP level at baseline. In this sense, the present study included middle age to elderly 
women (58.1 \pm 4.6 years), which despite being hypertensive, had medically controlled BP at baseline. Therefore, these characteristics may have masked the hypotensive effects of BJ.

In a previous study with hypertensive patients with chronic obstructive pulmonary disease [16], there was a hypotensive effect in DBP three hours after BJ ingestion containing $12.9 \mathrm{mmol}$ of $\mathrm{NO}_{3}{ }^{-}$. Different from the present study, they did not assess BJ consumption in combination with exercise, they used a lower dose of $\mathrm{NO}_{3}{ }^{-}$in $\mathrm{BJ}$, and they used a population with compromised cardiorespiratory capacity. In another study [20], patients with insufficient cardiac output using antihypertensive drugs consumed $140 \mathrm{~mL}$ of $\mathrm{BJ}$ containing $11.2 \mathrm{mmol}$ of $\mathrm{NO}_{3}{ }^{-}$and performed a 6 min walk, a maximal strength test, and a fatigue test. Despite evaluating BP post-exercise, they did not find a hypotensive effect associated with exercise or BJ supplementation. It should be noted that this evaluation occurred only $10 \mathrm{~min}$ after exercise, and the exercise protocol had more similarities to resistance exercise of high relative intensity. These characteristics differ greatly from the present study and may explain the absence of $\mathrm{PEH}$, since this effect is better reported in post-aerobic exercise [36]. The amount of $\mathrm{NO}_{3}{ }^{-}$ used in our study was based on previous studies investigating different doses of beetroot $/ \mathrm{NO}_{3}{ }^{-}$and blood pressure responses [37]. Wylie and colleagues [37] found that consumption of $\mathrm{NO}_{3}{ }^{-}$of up to $8.4 \mathrm{mmol}$ had dose dependent lowering effects on BP, but higher doses had no additional effects on BP. Therefore, the dose used in our study should be enough to increase NO availability and increase blood flow.

After exercise, local vasodilator mechanisms contribute to BP reduction, leading to a sustained vasodilatation response [4]. There are studies suggesting that NO released by endothelium could lead to this effect, even though this is not the main cause of PEH [16]. Thus, nitric oxide could be considered a potential contributor to sustained post-exercise vasodilatation and could be involved in PEH. It is known that shear stress and activation of endothelial receptors cause NO release by eNOS and the capacity of this pathway depends on the interaction of neuropeptide and mechanical stimuli [38]. PEH is more evident after moderate intensity aerobic exercise in people with hypertension [39]. Considering the initial level of $\mathrm{BP}$ as one of the factors that determines the magnitude of $\mathrm{PEH}[39,40]$, the use of antihypertensive drugs before exercise could mitigate this response. However, we found a PEH response even with antihypertensive drug use, which highlights the importance of exercise even in hypertensive patients under pharmacological therapy.

Additionally, the local vasodilatory response is not the only mechanism leading to PEH. Halliwill et al. [4] highlighted the possible explanations to PEH as: an adjustment of the baroreflex control to maintain a lower BP after exercise; a reduction in sympathetic nerve activity; a thermoregulatory readjustment; a vasodilation caused by release of $\mathrm{NO}$ and prostaglandins, which also cause reduction in $\alpha$-adrenergic sensitivity; and a vasodilation caused by the action of histamines. It is possible that one or more of these pathways could be the main cause of PEH rather than NO bioavailability. Interestingly, $\mathrm{BJ}$ has a notable influence on the bioavailability of $\mathrm{NO}$, and although this pathway does not seem to be the most important cause of PEH [4], some studies have shown that BJ intake can decrease BP $[16,28,33,37]$. Therefore, there is a possibility that increasing NO bioavailability by BJ consumption could change BP response. However, when considered along with other mechanisms causing PEH, there might be an attenuation or inhibition of other pathways involved that do not allow a significant additional effect in BP reduction.

In postmenopausal women, there is an increase in oxidative stress, due to the reduction in estrogen synthesis, impairing both vascular cell integrity and activity of antioxidant enzymes [41]. Furthermore, the impairment of oxidative balance has an important role in the pathogenesis of hypertension and may lead to impaired endothelium-dependent relaxation [42]. This decrease in relaxation capacity is associated with decreased NO production, increased cyclooxygenase-2 (COX-2) expression, and increased nicotinamide adenine dinucleotide phosphate oxidase (NADPH oxidase), of which COX-2 and NADPH oxidase are involved in stimulating the production of reactive oxygen species [42]. Thus, hypertensive women after menopause, have compromised blood vessel integrity, leading to endothelial dysfunction [42]. Ingestion of BJ [43] could be a clinically valid strategy to reduce the oxidative 
imbalance in this population, to increase the activity of antioxidant enzymes and blood flow, and to improve vascular relaxation dependent on shear stress derived from exercise.

A study [25] compared the responses to BJ intake in plasma, saliva, and urine and found that saliva is more sensitive to $\mathrm{NO}_{3}{ }^{-}$, with the $\mathrm{NO}_{2}{ }^{-}$concentration increasing seven times in saliva, three times in plasma, and four times in urine when compared to placebo. In agreement with these findings, in the current study there was a slight increase in salivary $\mathrm{NO}_{2}{ }^{-}$with PLA intake, showing that even with the low concentration of $\mathrm{NO}_{3}{ }^{-}$present in PLA, saliva is sensitive enough to respond to this stimulus [25]. This is likely due to the initial conversion of $\mathrm{NO}_{3}{ }^{-}$to $\mathrm{NO}_{2}{ }^{-}$that occurs in the mouth by salivary components [25,44], especially by oral microbiome [45]. The bacteria genus Veillonella spp. is of importance, increasing the conversion of $\mathrm{NO}_{3}{ }^{-}$to $\mathrm{NO}_{2}{ }^{-}$in the oral cavity, thus, assisting with the reintroduction of $\mathrm{NO}_{2}{ }^{-} / \mathrm{NO}_{3}{ }^{-}$in the pathway of $\mathrm{NO}$ production [45]. Recently, the clinical importance of the oral microbiome has been demonstrated in a hypertensive population by the use of antibacterial mouthwashes, which decreased the oral reduction of $\mathrm{NO}_{3}{ }^{-}$and increased blood pressure in this population [46]

Based on our results, there are other possibilities to explain the lack of an additional effect on PEH with $\mathrm{BJ}$ ingestion. The literature shows that the amount of $\mathrm{NO}_{3}{ }^{-}$consumed is sufficient to cause a hypotensive response in healthy individuals [37], however, the $\mathrm{NO}_{3}{ }^{-}$dose response could vary among different populations. Therefore, this dose may not have been enough for hypertensive postmenopausal women. Although there are indications that increased bioavailability of $\mathrm{NO}_{2}{ }^{-}$is associated with the increased bioavailability of $\mathrm{NO}[47,48]$, this conversion may not have been satisfactory to generate enough NO to potentiate vasodilation. In addition, the endothelium status of the participants is not known. As all participants have been diagnosed with hypertension for more than one year, there may be a deficiency in the production of eNOS, which could reduce NO production [49]. Thus, it is important to evaluate the $\mathrm{NO}$ response, to determine $\mathrm{NO}_{3}{ }^{-}$dose responses in different populations, and evaluate chronic consumption of BJ. Although there are no studies evaluating the interaction of antihypertensives and blood pressure response with exercise [50], it is important to consider that the study volunteers had pharmacologically controlled hypertension, and these drugs could influence blood pressure response after exercise. Furthermore, the bioavailability of NO may not be the main cause of PEH, and other mechanisms causing PEH were not evaluated in the present study, of which we highlight the activity of baroreflex and vasodilation caused by other substances, such as histamine and prostaglandins [4].

This study had limitations, since blood flow was not measured, and BJ intake and BP measurements were assessed in a short term, thus, our results cannot be extrapolated to chronic settings. The study participants were taking different anti-hypertensive medication, which could mask the effect of $\mathrm{NO}_{3}{ }^{-}$ on blood pressure. Our results suggest that moderate aerobic exercise is a good strategy to induce PEH and may be helpful for hypertension treatment. However, only one dose of BJ is not sufficient to cause an additional effect on PEH.

\section{Conclusions}

In conclusion, acute intake of beetroot juice does not change BP response mediated by moderate intensity aerobic exercise in hypertensive postmenopausal women, even though there is an increase in the bioavailability of salivary $\mathrm{NO}_{2}{ }^{-} / \mathrm{NO}$.

Author Contributions: A.L.A. participated in the data collection and analysis, performed statistical analysis, and wrote the manuscript; I.M.M. participated in the data collection and analysis, performed statistical analysis and contributed with the revision of the manuscript; V.H.V.C., T.C.F.d.S. and J.P.B. participated in the data collection, and contributed with the revision of the manuscript; A.M.M. contributed with the manuscript and English review; A.V.d.S., D.C.C., R.R.T. and F.S.E. participated in the data analysis, performed statistical analysis and contributed with the revision of the manuscript, E.P.d.O. participated in the study design, elaboration of the discussion and with the revision of the manuscript; G.M.P. contributed with the study design, data collection and analysis, statistical analysis, and with the manuscript elaboration and review. All authors read and approved the final manuscript. 
Funding: This work was funded by the Minas Gerais State Research Foundation (FAPEMIG) (APQ-01874-18) and FSE are grant recipients of the National Council for Scientific and Technological Development (CNPq - 308965/2015-9).

Conflicts of Interest: The authors declare no conflict of interest.

\section{References}

1. Lagranha, C.J.; Silva, T.L.A.; Silva, S.C.A.; Braz, G.R.F.; da Silva, A.I.; Fernandes, M.P.; Sellitti, D.F. Protective effects of estrogen against cardiovascular disease mediated via oxidative stress in the brain. Life Sci. 2018, 192, 190-198. [CrossRef]

2. Coylewright, M.; Reckelhoff, J.F.; Ouyang, P. Menopause and Hypertension An Age-Old Debate. Hypertension 2008, 51, 952-959. [CrossRef]

3. Malachias, M.; Souza, W.; Plavnik, F.; Rodrigues, C.; Brandão, A.; Neves, M.; Bortolotto, L.; Franco, R.; Poli-de-Figueiredo, C.; Jardim, P.; et al. $7^{a}$ Diretriz Brasileira De Hipertensão Arterial. In Arquivos Brasileiros de Cardiologia; 2016; Volume 107, ISBN 1435-232X (Electronic)r1434-5161 (Linking). Available online: http://publicacoes.cardiol.br/2014/diretrizes/2016/05_HIPERTENSAO_ARTERIAL.pdf (accessed on 3 November 2018).

4. Halliwill, J.R.; Buck, T.M.; Lacewell, A.N.; Romero, S.A. Postexercise hypotension and sustained postexercise vasodilatation: What happens after we exercise? Exp. Physiol. 2013, 98,7-18. [CrossRef]

5. Farah, C.; Nascimento, A.; Bolea, G.; Meyer, G.; Gayrard, S.; Lacampagne, A.; Cazorla, O.; Reboul, C. Key role of endothelium in the eNOS-dependent cardioprotection with exercise training. J. Mol. Cell. Cardiol. 2017, 102, 26-30. [CrossRef]

6. Ocampo, D.A.B.; Paipilla, A.F.; Marín, E.; Vargas-Molina, S.; Petro, J.L.; Pérez-Idárraga, A. Dietary Nitrate from Beetroot Juice for Hypertension: A Systematic Review. Biomolecules 2018, 8, 134. [CrossRef]

7. Eggebeen, J.; Kim-Shapiro, D.B.; Haykowsky, M.; Morgan, T.M.; Basu, S.; Brubaker, P.; Rejeski, J.; Kitzman, D.W. One Week of Daily Dosing With Beetroot Juice Improves Submaximal Endurance and Blood Pressure in Older Patients With Heart Failure and Preserved Ejection Fraction. JACC Heart Fail. 2016, 4, 428-437. [CrossRef]

8. Kenjale, A.A.; Ham, K.L.; Stabler, T.; Robbins, J.L.; Johnson, J.L.; VanBruggen, M.; Privette, G.; Yim, E.; Kraus, W.E.; Allen, J.D. Dietary nitrate supplementation enhances exercise performance in peripheral arterial disease. J. Appl. Physiol. 2011, 110, 1582-1591. [CrossRef]

9. Kelly, J.; Fulford, J.; Vanhatalo, A.; Blackwell, J.R.; French, O.; Bailey, S.J.; Gilchrist, M.; Winyard, P.G.; Jones, A.M. Effects of short-term dietary nitrate supplementation on blood pressure, O2 uptake kinetics, and muscle and cognitive function in older adults. AJP Regul. Integr. Comp. Physiol. 2013, 304, R73-R83. [CrossRef]

10. Bock, J.M.; Treichler, D.P.; Norton, S.L.; Ueda, K.; William, E.; Casey, D.P. Inorganic nitrate supplementation enhances functional capacity and lower-limb microvascular reactivity in patients with peripheral artery disease. Nitric Oxide 2018, 80, 45-51. [CrossRef]

11. Siervo, M.; Oggioni, C.; Mathers, J.C.; Celis-Morales, C.; Ashor, A.W.; Jakovljevic, D.G.; Trenell, M.; Houghton, D.; Trenell, M.; Mathers, J.C.; et al. Dietary nitrate does not affect physical activity or outcomes in healthy older adults in a randomized, cross-over trial. Nutr. Res. 2016, 36, 1361-1369. [CrossRef]

12. Woessner, M.; VanBruggen, M.D.; Pieper, C.F.; Sloane, R.; Kraus, W.E.; Gow, A.J.; Allen, J.D. Beet the Best? Circ. Res. 2018, 123, 654-659. [CrossRef]

13. Bahadoran, Z.; Mirmiran, P.; Kabir, A.; Azizi, F.; Ghasemi, A. The Nitrate-Independent Blood Pressure-Lowering Effect of Beetroot Juice: A Systematic Review and Meta-Analysis. Adv. Nutr. 2017, 8, 830-838. [CrossRef]

14. Jackson, J.K.; Patterson, A.J.; Macdonald-wicks, L.K.; Oldmeadow, C.; Mcevoy, M.A. The role of inorganic nitrate and nitrite in cardiovascular disease risk factors: A systematic review and meta-analysis of human evidence. Nutr. Rev. 2018, 76, 348-371. [CrossRef]

15. Stanaway, L.; Rutherfurd-Markwick, K.; Page, R.; Ali, A. Performance and health benefits of dietary nitrate supplementation in older adults: A systematic review. Nutrients 2017, 9, 1171. [CrossRef]

16. Curtis, K.J.; O’Brien, A.K.; Tanner, R.J.; Polkey, J.I.; Minnion, M.; Feelisch, M.; Polkey, M.I.; Edwards, M.; Hopkinson, N.S. Acute dietary nitrate supplementation and exercise performance in COPD: A double-blind, placebo-controlled, randomised controlled pilot study. PLOS ONE 2015, 10, e0144504. [CrossRef] 
17. Lansley, K.E.; Winyard, P.G.; Bailey, S.J.; Vanhatalo, A.; Wilkerson, D.P.; Blackwell, J.R.; Gilchrist, M.; Benjamin, N.; Jones, A.M. Acute dietary nitrate supplementation improves cycling time trial performance. Med. Sci. Sports Exerc. 2011, 43, 1125-1131. [CrossRef]

18. Thompson, C.; Vanhatalo, A.; Jell, H.; Fulford, J.; Carter, J.; Nyman, L.; Bailey, S.J.; Jones, A.M. Dietary nitrate supplementation improves sprint and high-intensity intermittent running performance. Nitric Oxide 2016, 61, 55-61. [CrossRef]

19. Clifford, T.; Berntzen, B.; Davison, G.W.; West, D.J.; Howatson, G.; Stevenson, E.J. Effects of beetroot juice on recovery of muscle function and performance between bouts of repeated sprint exercise. Nutrients 2016, 8 , 506. [CrossRef]

20. Coggan, A.R.; Leibowitz, J.L.; Spearie, C.A.; Kadkhodayan, A.; Thomas, D.P.; Ramamurthy, S.; Mahmood, K.; Park, S.; Waller, S.; Farmer, M.; et al. Acute Dietary Nitrate Intake Improves Muscle Contractile Function in Patients with Heart Failure: A Double-Blind, Placebo-Controlled, Randomized Trial. Circ. Heart Fail. 2015, 8, 914-920. [CrossRef]

21. Barbosa, C.D.; Costa, J.G.; Giolo, J.S.; Rossato, L.T.; Nahas, P.C.; Mariano, I.M.; Batista, J.P.; Puga, G.M.; de Oliveira, E.P. Isoflavone supplementation plus combined aerobic and resistance exercise do not change phase angle values in postmenopausal women: A randomized placebo-controlled clinical trial. Exp. Gerontol. 2019, 117, 31-37. [CrossRef]

22. Karvonen, M.J.; Kentala, E.; Mustala, O. The effects of training on heart rate; a longitudinal study. Ann. Med. Exp. Biol. Fenn. 1957, 35, 307-315.

23. Borg, G.A. Psychophysical bases of perceived exertion. Med. Sci. Sports Exerc. 1982, 14, 377-381. [CrossRef]

24. De Castro, T.F.; Manoel, F.D.A.; Figueiredo, D.H.; Figueiredo, D.H.; Machado, F.A. Effect of beetroot juice supplementation on 10-km performance in recreational runners. Appl. Physiol. Nutr. Metab. 2018, 44, 90-94. [CrossRef]

25. Bondonno, C.P.; Liu, A.H.; Croft, K.D.; Ward, N.C.; Shinde, S.; Moodley, Y.; Lundberg, J.O.; Puddey, I.B.; Woodman, R.J.; Hodgson, J.M. Absence of an effect of high nitrate intake from beetroot juice on blood pressure in treated hypertensive individuals: A randomized controlled trial. Am. J. Clin. Nutr. 2015, 102, 368-375. [CrossRef]

26. Navazesh, M. Methods for Collecting Saliva. Ann. N. Y. Acad. Sci. 1993, 694, 72-77. [CrossRef]

27. Kurose, I.; Wolf, R.; Grisham, M.B.; Granger, D.N. Effects of an endogenous inhibitor of nitric oxide synthesis on postcapillary venules. Am. J. Physiol. 1995, 268, H2224-H2231. [CrossRef]

28. Vanhatalo, A.; Bailey, S.J.S.; Blackwell, J.R.J.; DiMenna, F.J.F.; Pavey, T.G.; Wilkerson, D.P.; Benjamin, N.; Winyard, P.G.P.; Jones, A.M. Acute and chronic effects of dietary nitrate supplementation on blood pressure and the physiological responses to moderate-intensity and incremental exercise. Am. J. Physiol. Regul. Integr. Comp. Physiol. 2010, 299, R1121-R1131. [CrossRef]

29. Betteridge, S.; Bescós, R.; Martorell, M.; Pons, A.; Garnham, A.P.; Stathis, C.C.; McConell, G.K. No effect of acute beetroot juice ingestion on oxygen consumption, glucose kinetics, or skeletal muscle metabolism during submaximal exercise in males. J. Appl. Physiol. 2016, 120, 391-398. [CrossRef]

30. Kim, J.-K.; Moore, D.J.; Maurer, D.G.; Kim-Shapiro, D.B.; Basu, S.; Flanagan, M.P.; Skulas-Ray, A.C.; Kris-Etherton, P.; Proctor, D.N. Acute dietary nitrate supplementation does not augment submaximal forearm exercise hyperemia in healthy young men. Appl. Physiol. Nutr. Metab. 2015, 40, 122-128. [CrossRef]

31. Bond, V., Jr.; Curry, B.H.; Adams, R.G.; Haddad, G.E. Cardiorespiratory function associated with dietary nitrate supplementation. Appl. Physiol. Nutr. Metab. 2014, 39, 168-172. [CrossRef]

32. Dos Santos Baião, D.; Conte-Junior, C.A.; Paschoalin, V.M.F.; Alvares, T.S. Beetroot juice increase nitric oxide metabolites in both men and women regardless of body mass. Int. J. Food Sci. Nutr. 2016, 67, 40-46. [CrossRef]

33. Berry, M.J.; Justus, N.W.; Hauser, J.I.; Case, A.H.; Helms, C.C.; Basu, S.; Rogers, Z.; Lewis, M.T.; Miller, G.D. Dietary nitrate supplementation improves exercise performance and decreases blood pressure in COPD patients. Nitric Oxide-Biol. Chem. 2015, 48, 22-30. [CrossRef]

34. Hohensinn, B.; Haselgrübler, R.; Müller, U.; Stadlbauer, V.; Lanzerstorfer, P.; Lirk, G.; Höglinger, O.; Weghuber, J. Sustaining elevated levels of nitrite in the oral cavity through consumption of nitrate-rich beetroot juice in young healthy adults reduces salivary pH. Nitric Oxide-Biol. Chem. 2016, 60, 10-15. [CrossRef] 
35. Siervo, M.; Lara, J.; Jajja, A.; Sutyarjoko, A.; Ashor, A.W.; Brandt, K.; Qadir, O.; Mathers, J.C.; Benjamin, N.; Winyard, P.G.; et al. Ageing modifies the effects of beetroot juice supplementation on 24-h blood pressure variability: An individual participant meta-analysis. Nitric Oxide-Biol. Chem. 2015, 47, 97-105. [CrossRef]

36. Cornelissen, V.A.; Smart, N.A. Exercise Training for Blood Pressure: A Systematic Review and Meta-analysis. J. Am. Heart Assoc. 2013, 2, e004473. [CrossRef]

37. Wylie, L.J.; Kelly, J.; Bailey, S.J.; Blackwell, J.R.; Skiba, P.F.; Winyard, P.G.; Jeukendrup, A.E.; Vanhatalo, A.; Jones, A.M. Beetroot juice and exercise: Pharmacodynamic and dose-response relationships. J. Appl. Physiol. 2013, 115, 325-336. [CrossRef]

38. Quillon, A.; Fromy, B.; Debret, R. Endothelium microenvironment sensing leading to nitric oxide mediated vasodilation: A review of nervous and biomechanical signals. Nitric Oxide-Biol. Chem. 2015, 45, 20-26. [CrossRef]

39. Gomes Anunciação, P.; Doederlein Polito, M. A review on post-exercise hypotension in hypertensive individuals. Arq. Bras. Cardiol. 2011, 96, 100-109.

40. Reboussin, D.M.; Allen, N.B.; Griswold, M.E.; Guallar, E.; Hong, Y.; Lackland, D.T.; Miller, E.P.R.; Polonsky, T.; Thompson-Paul, A.M.; Vupputuri, S. Systematic Review for the 2017 ACC/AHA/AAPA/ABC/ACPM/AGS/APhA/ASH/ASPC/NMA/PCNA Guideline for the Prevention, Detection, Evaluation, and Management of High Blood Pressure in Adults: A Report of the American College of Cardiology/American Heart Association. J. Am. Coll. Cardiol. 2018, 71, 2176-2198. [CrossRef]

41. Jarrete, A.P.; Novais, I.P.; Nunes, H.A.; Puga, G.M.; Delbin, M.A.; Zanesco, A. Influence of aerobic exercise training on cardiovascular and endocrine-inflammatory biomarkers in hypertensive postmenopausal women. J. Clin. Transl. Endocrinol. 2014, 1, 108-114. [CrossRef]

42. Korsager Larsen, M.; Matchkov, V.V. Hypertension and physical exercise: The role of oxidative stress. Medicina 2016, 52, 19-27. [CrossRef] [PubMed]

43. Clifford, T.; Howatson, G.; West, D.J.; Stevenson, E.J. The potential benefits of red beetroot supplementation in health and disease. Nutrients 2015, 7, 2801-2822. [CrossRef] [PubMed]

44. Bedale, W.; Sindelar, J.J.; Milkowski, A.L. Dietary nitrate and nitrite: Benefits, risks, and evolving perceptions. Meat Sci. 2016, 120, 85-92. [CrossRef] [PubMed]

45. Blekkenhorst, L.C.; Bondonno, N.P.; Liu, A.H.; Ward, N.C.; Prince, R.L.; Lewis, J.R. Nitrate, the oral microbiome, and cardiovascular health: A systematic literature review of human and animal studies. Am. J. Clin. Nutr. 2018, 107, 504-522. [CrossRef] [PubMed]

46. Bondonno, C.P.; Liu, A.H.; Croft, K.D.; Considine, M.J.; Puddey, I.B.; Woodman, R.J.; Hodgson, J.M. Antibacterial Mouthwash Blunts Oral Nitrate Reduction and Increases Blood Pressure in Treated Hypertensive Men and Women. Am. J. Hypertens. 2015, 28, 572-575. [CrossRef] [PubMed]

47. Duncan, C.; Dougall, H.; Ohnston, P.; Green, S.; Brogan, R.; Leifer, C.; Smith, L.; Gowen, M.; Benjamin, N. Chemical generation of nitric oxide in the mouth from the enterosalivary circulation of dietary nitrate. Nat. Med. 1995, 1, 546. [CrossRef] [PubMed]

48. Kim-Shapiro, D.B.; Gladwin, M.T. Mechanisms of Nitrite Bioactivation. Nitric Oxide 2014, 38, 58-68. [CrossRef]

49. Förstermann, U. Nitric oxide and oxidative stress in vascular disease. Eur. J. Physiol. 2010, 459, $923-939$. [CrossRef]

50. Naci, H.; Salcher-konrad, M.; Dias, S.; Blum, M.R.; Sahoo, S.A.; Nunan, D.; Ioannidis, J.P.A. How does exercise treatment compare with antihypertensive medications? A network meta-analysis of 391 randomised controlled trials assessing exercise and medication effects on systolic blood pressure. Brith J. Sprots Med. 2018, 1-12. [CrossRef]

(C) 2019 by the authors. Licensee MDPI, Basel, Switzerland. This article is an open access article distributed under the terms and conditions of the Creative Commons Attribution (CC BY) license (http://creativecommons.org/licenses/by/4.0/). 